\title{
DESIGNING AND MANUFACTURING A MULTI-MOLD ELECTROMAGNETIC CASTING MACHINE
}

\author{
Dr. M. Ramadan Ahmed \\ Associate Professor, Faculty of Engineering, Helwan University, Cairo Egypt
}

\begin{abstract}
This paper presents a research work has been done through a project for designing, manufacturing, and installing a new electromagnetic caster (EMC) of double molds (double rectangular ingots of aluminum) in the Egyptalum Company. The main design problem is to terminate the effects of the electromagnetic coupling, between the two molds, on the performance of the casting machine. For this purpose a 3D multi-body Boundary Element formulation is derived and used to form the core of an iterative solution. This solution is used for estimating the line frequency and currents, locating the one turn induction coils and the electromagnetic screen (EMS), and finally positioning the two molds inside the machine.
\end{abstract}

\section{Keywords: Magnetic Forces, Static Head, Surface Estimation, Multi-Ingot, Magnetic Coupling, Induction Coil Location, EM Screen Location, and Line Current \& Frequency Estimation.,}

\section{INTRODUCTION}

In the $3 \mathrm{D}$ eddy current and free surface calculations, the obtaining of an accurate numerical solution with reasonable size and less computation efforts is still undertaken in many recent articles. Such a solution is urgently required for designing and developing an electromagnetic caster which is not only classified as a 3D eddy current problem but it also involves more than one conducting region having free boundary which is unknown a priori. In this application, the electromagnetic forces play the main part in confining the freestanding column of the melt while the surface layer freezes. Therefore, the main design problem is to locate the confinement coil and the fieldshaping shield so as to obtain the electromagnetic force distributions required for supporting the resulting free surface [1].
Also, both line frequency and current have significant effects on the performance of this caster [2]. For this class of applications, a recent $3 \mathrm{D}$ iterative solution was developed for the analysis of an electromagnetic caster (EMC) of aluminum rectangular ingot installed in the Egyptalum Company [3-4]. The solution was used to design and manufacture a new electromagnetic casting machine producing a single rectangular ingot of aluminum. The performance of the new designed machine was satisfactory and it was encouraging to extend the research work for developing a multi-mold electromagnetic caster.

This paper presents research efforts have been done for designing, manufacturing, and installing a new electromagnetic casting machine with double molds, (two rectangular ingots of aluminum) in the Egyptalum Company. For this purpose a 3D multi- 
body Boundary Element formulation is derived and used to form the core of an iterative solution. This solution is used for estimating the line frequency and currents, locating the induction coils and the electromagnetic screens, and finally positioning the two molds inside the machine. Also, the calculations of the magnetic fields and the electromagnetic pressure distributions within the casting machine are considered.

\section{3D BOUNDARY ELEMENT FORMULATION}

For the present application having the basic configuration shown in Fig. 1, a 3D Boundary Element (BE) - Impedance Boundary Condition (IBC) formulation is derived for the free surface shape and magnetic field calculations.

In this formulation, the IBC is applied to the resistively molten aluminum region, where the electromagnetic penetration depth is shallow; while the full $\mathrm{BE}$ formulation is used to present the field shaping turn. The derived BE-IBC formulation was obtained as follows:

\section{NUMERICAL RESULTS}

The present iterative solution was used for estimating the designed electrical and mechanical parameters of an electromagnetic caster with two molds sized 2 ( $\mathrm{L}=1050 \mathrm{~mm} \&$ $\mathrm{W}=280 \mathrm{~mm}$ ) shown in fig. 1 In this solution, the restriction of completely eliminated the electromagnetic coupling effect between the two molds was applied. These parameters were evaluated as follows:

The Supply Current: 2 x 260 A.

The Supply Frequency: $1975 \mathrm{~Hz}$.

Capacitor Bank: 2 x $150 \mu \mathrm{F} / 800 \mathrm{~V}$.

$1 \varphi$ Transformer: $2 \times 1600$ KVA.

Separation Distance between the Two Molds: $930 \mathrm{~mm}$.

Screen Position above the Inductor Center: $10 \mathrm{~mm}$.

$$
\begin{aligned}
1 / 2 \mathrm{H}_{\mathrm{m}}(\zeta) \bullet \mathrm{C}=\mathrm{H}_{\mathrm{m}}^{\mathrm{i}}(\zeta) \bullet \mathrm{C} & +\left[\left[\mathrm{L}_{\mathrm{m} \Omega \circ}^{(1)} \mathrm{H}_{\mathrm{m}}(\eta)+\left(\mathrm{z}_{\mathrm{sm}} / \mathrm{z}_{\Omega \circ}\right) \mathrm{L}_{\mathrm{m} \Omega \circ}^{(2)}\left(\mathrm{n}_{\mathrm{m}} \times \mathrm{H}_{\mathrm{m}}(\eta)\right)\right]\right. \\
& \left.+\left(1 / \mathrm{z}_{\Omega \circ}\right) \mathrm{L}_{\mathrm{s} \Omega \circ}^{(2)} \mathrm{E}_{\mathrm{s}}(\eta)+\mathrm{L}_{\mathrm{s} \Omega \circ}^{(1)} \mathrm{H}_{\mathrm{s}}(\eta)\right]_{\mathrm{M} 11} \\
& +\left[\left[\mathrm{L}_{\mathrm{m} \Omega \circ}^{(1)} \mathrm{H}_{\mathrm{m}}(\eta)+\left(\mathrm{z}_{\mathrm{sm}} / \mathrm{z}_{\Omega \circ}\right) \mathrm{L}_{\mathrm{m} \Omega \circ}^{(2)}\left(\mathrm{n}_{\mathrm{m}} \times \mathrm{H}_{\mathrm{m}}(\eta)\right)\right]\right. \\
& \left.+\left(1 / \mathrm{z}_{\Omega \circ}\right) \mathrm{L}_{\mathrm{s} \Omega \circ}^{(2)} \mathbf{E}_{\mathrm{s}}(\eta)+\mathrm{L}_{\mathrm{s} \Omega \circ}^{(1)} \mathrm{H}_{\mathrm{s}}(\eta)\right]_{\mathrm{M} 12}
\end{aligned}
$$

$$
\begin{aligned}
& E_{s}(\zeta) \bullet C=\left[2 Y_{\Omega \circ} /\left(Y_{s}+Y_{\Omega \circ}\right)\right] E_{m}^{i}(\zeta) \bullet C \\
& +\left[2 /\left(Y_{s}+Y_{\Omega \circ}\right)\right]\left[\left(Z_{s m} Y_{\Omega \circ} L_{m \Omega o}^{(1)}\left(n_{m} \times H_{m}(\eta)\right)+L_{m \Omega 0}^{(2)} H_{m}(\eta)\right)\right. \\
& \left.-\left(Y_{s} L_{s}^{(1)}-Y_{\Omega 0} L_{s \Omega 0}^{(1)}\right) E_{s}(\eta)-\left(L_{s}^{(2)}-L_{s \Omega o}^{(2)}\right) H_{s}(\eta)\right]_{M 11} \\
& +\left[2 /\left(Y_{s}+Y_{\Omega o}\right)\right]\left[\left(Z_{s m} Y_{\Omega \circ} L_{m \Omega o}^{(1)}\left(n_{m} \times H_{m}(\eta)\right)+L_{m \Omega 0}^{(2)} H_{m}(\eta)\right)\right. \\
& \left.-\left(Y_{s} L_{s}^{(1)}-Y_{\Omega \circ} L_{s \Omega o}^{(1)}\right) E_{s}(\eta)-\left(L_{s}^{(2)}-L_{s \Omega o}^{(2)}\right) H_{s}(\eta)\right]_{M 12} \\
& \mathrm{H}_{\mathrm{m}}(\zeta) \bullet \mathrm{C}=\left[2 \mathrm{Z}_{\Omega \circ} /\left(\mathrm{Z}_{\mathrm{s}}+\mathrm{Z}_{\Omega \circ}\right)\right] \mathrm{H}_{\mathrm{s}}^{\mathrm{i}}(\zeta) \bullet \mathrm{C} \\
& +\left[2 /\left(\mathrm{Z}_{\mathrm{s}}+\mathrm{Z}_{\Omega_{0}}\right)\right]\left[\left(\mathrm{Z}_{\mathrm{sm}} / \mathrm{Z}_{\Omega_{\mathrm{o}}}\right) \mathrm{L}_{\mathrm{m} \Omega_{\mathrm{o}}}^{(2)}\left(\mathrm{n}_{\mathrm{m}} \times \mathrm{H}_{\mathrm{m}}(\eta)\right)+\mathrm{L}_{\mathrm{m} \Omega_{0}}^{(1)} \mathrm{H}_{\mathrm{m}}(\eta)\right. \\
& \left.-\left(L_{s}^{(2)}-L_{s \Omega 0}^{(2)}\right) E_{s}(\eta)-\left(Z_{s} L_{s}^{(1)}-Z_{\Omega \circ} L_{s \Omega 0}^{(1)}\right) H_{s}(\eta)\right]_{M 11} \\
& +\left[2 /\left(Z_{s}+Z_{\Omega o}\right)\right]\left[\left(Z_{s m} / Z_{\Omega o}\right) L_{m \Omega o}^{(2)}\left(n_{m} \times H_{m}(\eta)\right)+L_{m \Omega_{0}}^{(1)} H_{m}(\eta)\right. \\
& \left.-\left(L_{s}^{(2)}-L_{s \Omega 0}^{(2)}\right) E_{s}(\eta)-\left(Z_{s} L_{s}^{(1)}-Z_{\Omega \circ} L_{s \Omega 0}^{(1)}\right) H_{s}(\eta)\right]_{M 12}
\end{aligned}
$$




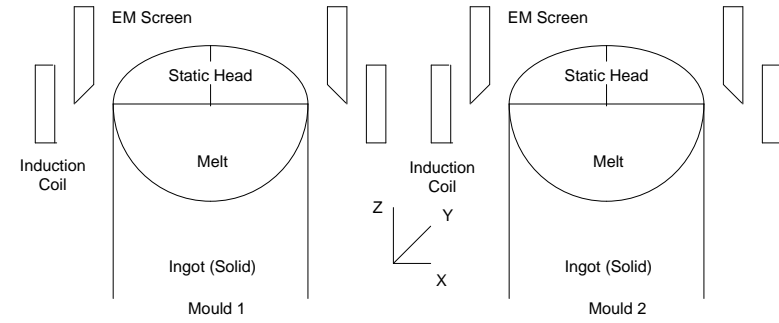

Fig.1. Basic configuration of the multi-mold electromagnetic caster

The validity of these parameters was tested numerically as the two molds were operated like a two-isolated single mold. The electromagnetic coupling effect was totally eliminated as no obvious change in the magnetic field distribution on the surfaces of both molds was recorded. The magnetic field distributions as well as the resulting free surface of a single mold were compared with the corresponding results when the electromagnetic casting machine with two molds was operated. The values of the magnetic field intensity obtained are plotted against the per unit value of the contour length considered in two directions such as along $z-y$ or $x-y$. The first contour is beginning from the point of meeting the solid and the melt regions at the midpoint of the width along $y$-axis $(L / 2,0,0)$ to go along the $\mathrm{z}-$ direction to the top center point of the static head $(0,0, z)$. While the second contour $x-y$ is beginning from the point of meeting the solid and the melt regions at the midpoint of the length along $\mathrm{x}$-axis $(0, \mathrm{~W} / 2,0)$ to the midpoint of the width along the $y$-axis $(\mathrm{L} / 2, \mathrm{~W} / 2,0)$. The results given in figures 2 , and 3 shows that the values of the magnetic fields are identical and the coupling between the two molds is totally terminated. Figure 4 shows the resulting equilibrium free surface of the two molds operation compared with the single mold operation when the supply frequency reaches $(2500 \mathrm{~Hz})$ the ceiling values of the power supply installed. This case was particularly considered because of its possibility to be occurred if a capacitor unit is shouting down during the normal operation. The designed electromagnetic casting machine was manufactured and installed in the company by the middle of 95 in the working field. The machine was tested in producing two identical aluminum ingots lengthen $5 \mathrm{~m}$ through a normal and stable operation of two and half hours period. The different stages of installation and preparing the machine as well as the test were recorded in photos given below in figures 5-9. Figure 5 shows the bases of the new two molds. These bases are used in the beginning of the casting process to support the aluminum column until its sides are completely solidified. Figure 6 shows the preparing of the machine and adjusting the pressure of the water shower for cooling the melt part of the ingot. Figures 7 and 8 shows the machine during the casting process. Figure 9 shows the final product of the two aluminum ingots.

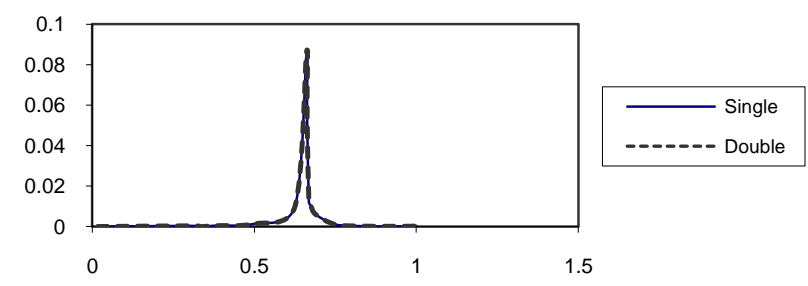

Fig. 2. Magnetic Field Distribution Along The zy-contour

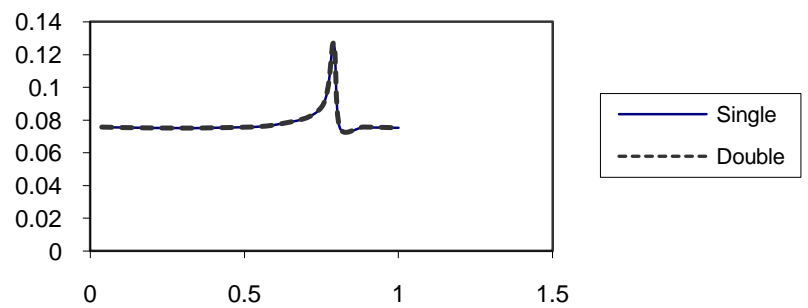

Fig.3. Magnetic Field Distribution Along The xy-contour

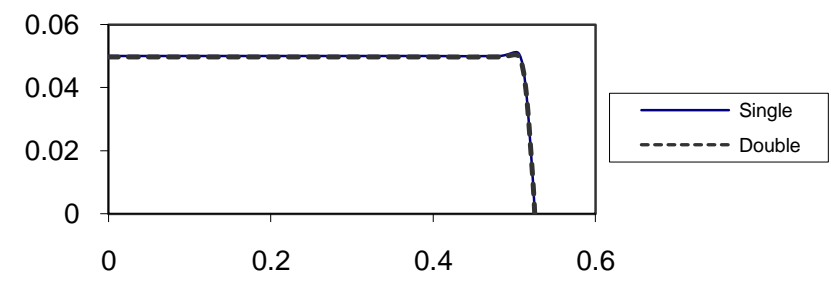

Fig. 4. The Estimated Free Surface of The Melt Region 


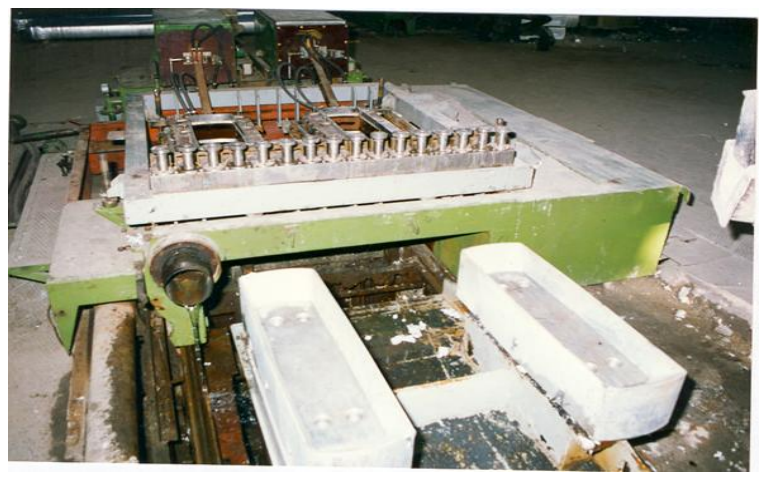

Fig. 5. The bases of the molds

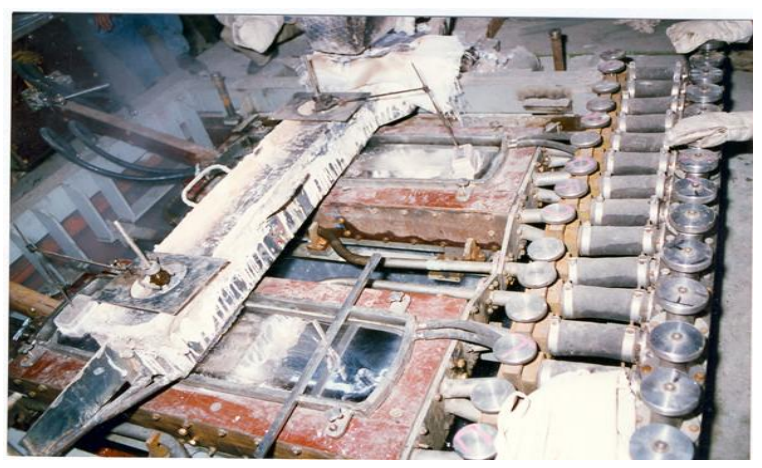

Fig. 6. Preparing the EMC machine

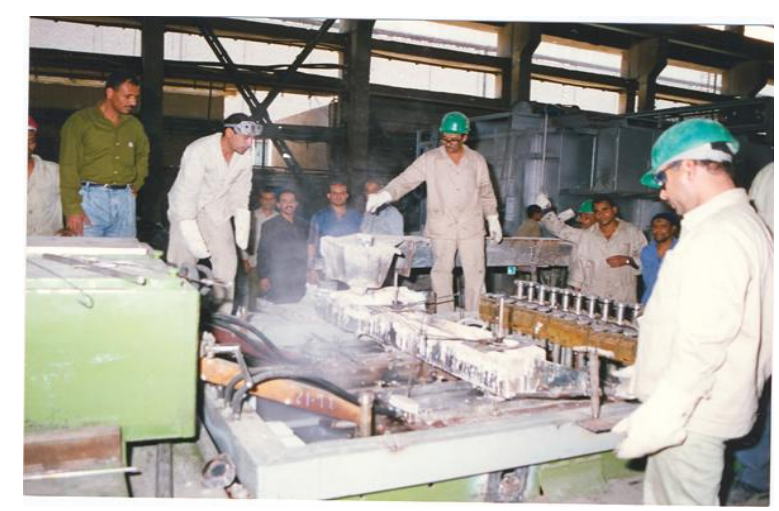

Fig. 7. The EMC during the casting process

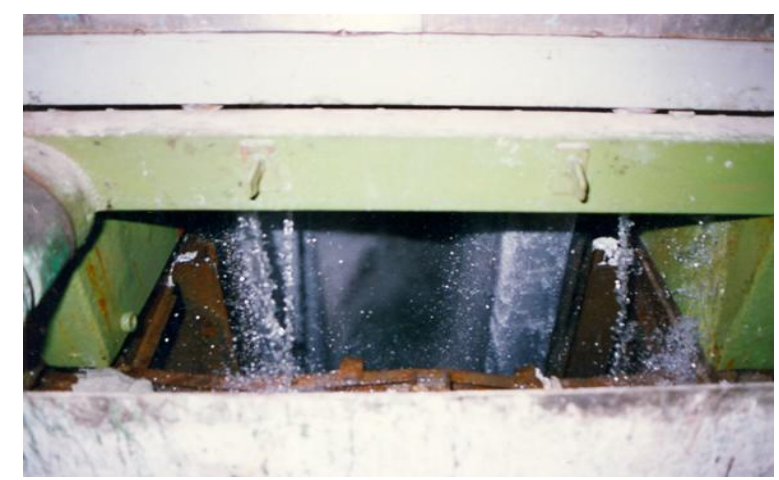

Fig. 8. Casting the two molds

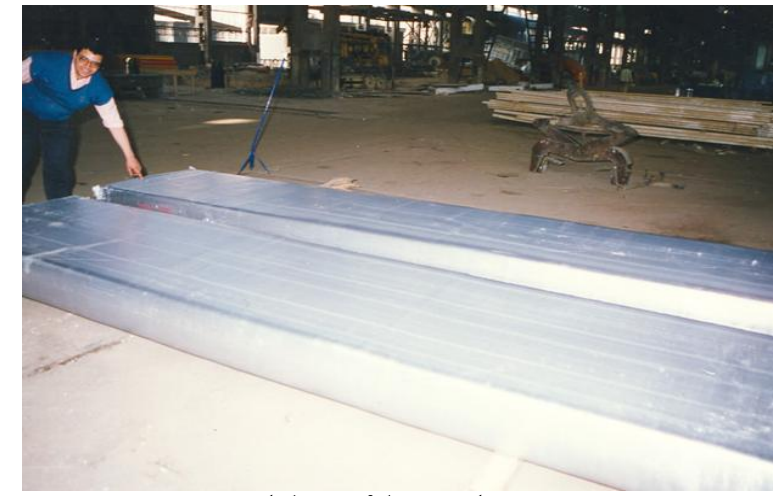

Fig. 9. Final shape of the two aluminum ingots

\section{CONCLUSIONS}

The present paper is concluding a research work has been donning in Egyptalum Company in the period from 1993 to 1996. The main objective of this work was developing a multi-ingot electromagnetic casting machine. Numerical solution based on 3D iterative boundary element technique was used to estimate the electrical and mechanical parameters of the new multi mould machine. The validity of these parameters was tested numerically as the two molds were operated like a two-isolated single mold. The electromagnetic coupling effect was totally eliminated as no obvious change in the magnetic field distribution on the surfaces of both molds was recorded. The magnetic field distributions as well as the resulting free surface of a single mold were compared with the corresponding results when the electromagnetic casting machine with two molds was operated. The case of supplying the new machine with a line current at 2500 $\mathrm{Hz}$ (supply ceiling value) was particularly considered because of its possibility to be occurred if a capacitor unit is shouting down during the normal operation. The designed electromagnetic casting machine was manufactured and installed in the company by the end of 1995 in the working field. The machine was tested in producing two identical aluminum ingots lengthen $5 \mathrm{~m}$ through a normal and stable operation of two and half 
hours period. The different stages of installation and preparing the machine as well as the test were recorded in photos given.

\section{REFERENCES}

[1] M. Ramadan Ahmed, J.D. Lavers, "Boundary element analysis of the electromagnet casting mould”, IEEE Trans. On Magnetics, Vol. 25 (4), 1989, pp 2843-2845.

[2] B.Q. Li and J.W. Evans, "Three-dimensional calculation of fields in electromagnetic caster", Casting of near Net Shape Products, The Metallurgical Society, 1988, pp 411-421.

[3] M. Ramadan Ahmed, K.F. Aly, I. Moustafa, "Three-dimensional iterative solution for the multiconductor eddy current and free surface calculations", J. Appl. Phys. Vol.75 (10), May 15, 1994, pp 6030-6032.

[4] M. Ramadan Ahmed, "Magnetic Semi-Levitation Application: The Analysis of an Electromagnetic Caster Machine", Third Saudi Technical Conference and Exhibition, 11-15 December 2004. 


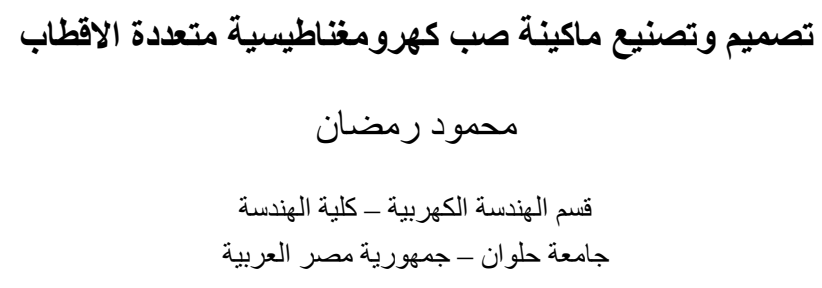

الملخص:

تقدم هذه الورقة البحثية العمل البحثي الذي تم تنفيذه من خلال مشروع لتصميم وتصنيع وتركيب ماكينة صب كهرومغناطيسية جديدة ثنائية القطب (مستطيلة المقطع من الالمنيوم) في احدى الثركات المصرية.

كانت اهم مشاكل التصميم هي ملاشاة التأثثر الكهرومغناطيسي بين القطبين على أداء ماكينة الصب. ولهذا الغرض تم بناء نموذج ثناثي الابعاد يعتمد على مبدأ العناصر المحيطة وتم استخدام هذا النموذج في استنباط اساس الحل الذي يعتمد على الحل التتابعي. هذا الحل تم استخدامه في تقدير تردد الخط وشدة التيار الكهربي و أفضل مكان للملف التأثيري وللثاشة الكهرومغناطيسية وأخير ا مكان القطبين داخل ماكينة الصب. 